\title{
The prognostic role of hemoglobin levels in patients undergoing concurrent chemo-radiation for anal cancer
}

\author{
Pierfrancesco Franco ${ }^{1 *}$ (D) Francesco Montagnani ${ }^{2}$, Francesca Arcadipane ${ }^{3}$, Chiara Casadei ${ }^{4}$, Kalliopi Andrikou ${ }^{5}$, \\ Stefania Martini ${ }^{1}$, Giuseppe Carlo lorio ${ }^{1}$, Mario Scartozzi ${ }^{6}$, Massimiliano Mistrangelo $^{7}$, Lorenzo Fornaro ${ }^{8}$, \\ Paola Cassoni ${ }^{9}$, Stefano Cascinu ${ }^{5}$, Umberto Ricardi ${ }^{1}$ and Andrea Casadei Gardini ${ }^{4}$
}

\begin{abstract}
Background: Concurrent chemo-radiation (CT-RT) is a standard therapy for squamous cell carcinoma of anal canal. Different clinical and biological factors may potentially affect outcome. We investigated the prognostic role of baseline hemoglobin $(\mathrm{Hb})$ in a cohort of anal cancer patients submitted to CT-RT with 5-fluorouracil and mitomycin C.

Methods: Up to 161 patients with clinical stage T1-T4/NO-N3/M0 were treated. Response was assessed at 6 weeks and thereafter at 3, 6 and 12 months. Two different approaches were used:a)simultaneous integrated boost following RTOG 05-29 indications;b)first sequence of 45Gy/25 fractions to the pelvis followed by 9-14.4 Gy/5-8 fractions to the macroscopic disease. Primary endpoints were progression-free survival (PFS) and overall survival (OS).

Results: On multivariate analysis, pre-treatment Hb level had a significant correlation to OS (HR:0.53;95\% Cl:0.33-0.87; $p=0.001$ ), but not to PFS (HR:0.78;95\% Cl:0.53-1.15; $p=0.12$ ) Patients with pre-treatment Hb $\geq 12 \mathrm{~g} / \mathrm{dl}$ had 5-year PFS and OS of $82.2 \%$, compared to $29.3 \%$ and $32.8 \%$ for those below the threshold. The likelihood to achieve a complete remission increased by 5.6\% for every single-unit ( $\mathrm{g} / \mathrm{dl}$ ) increase in baseline $\mathrm{Hb}$ level over $11 \mathrm{~g} / \mathrm{dl}$. On multivariate analysis, response to treatment had a significant correlation to PFS (incomplete vs complete response - HR:5.43;95\% Cl: 2.75-10.7; $p<0.0001)$ and OS (HR: 6.96;95\% Cl:2.96-16.5; $p<0.0001)$.

Conclusions: We showed that baseline $\mathrm{Hb}$ level is a strong indicator for poor response to RT-CT in anal cancer patients. A close clinical monitoring for incomplete response to treatment should be advised in patients with low pretreatment $\mathrm{Hb}$. The hypothesis that the preservation of adequate $\mathrm{Hb}$ level during treatment may lead to a better outcome needs prospective evaluation.
\end{abstract}

Keywords: Anal cancer, Hematologic toxicity, Anemia, Hemoglobin, Prognostic factors

\section{Background}

Anal cancer is considered a rare tumor, accounting for $6 \%$ of all malignancies arising in the ano-rectal region [1]. Concurrent chemo-radiation (CT-RT) is the standard therapeutic option in this setting, providing consistent clinical outcomes [2, 3]. Prospective trials reported loco-regional recurrence (LRR) rates ranging from $60 \%$ to $80 \%$ and overall survival (OS) rates from $65 \%$ to $78 \%$ at 3-5 years, depending on disease and patient

\footnotetext{
* Correspondence: pierfrancesco.franco@unito.it

1 Department of Oncology, Radiation Oncology, University of Turin at AOU

Citta' della Salute e della Scienza, Via Genova 3, 10126 Turin, Italy

Full list of author information is available at the end of the article
}

characteristics [4-8]. Given the relatively infrequent occurrence of squamous cell carcinoma of the anal canal, the correlation between clinical factors and outcome has always been challenging to assess [9]. Most of the factors explored are related to tumor such as size and nodal status, while patient features are mostly related to gender and race [10]. Some of the randomized phase III trials who set the standard for the treatment of anal cancer, such as the European Organization for Research and Treatment of Cancer (EORTC) trial 22861, the Radiotherapy and Oncology Group (RTOG) trial 98-11 and the Anal Cancer Trial-I study (ACT-I) provided analyses on prognostic factors $[5,7,11]$. The EORTC 22861 has 
shown that male sex, nodal involvement and skin ulceration are independent predictors of LRR and OS [5]. The RTOG 98-11 trial found out a significant correlation between male sex and nodal involvement and LRR and established tumor size $(>5 \mathrm{~cm})$ as an independent predictor of disease-free-survival (DFS) and OS [12]. Mature outcomes from the ACT-I trial supported evidence for palpable lymphnodes and male sex as prognostic factors for LRR and OS and interestingly, showed that lower baseline hemoglobin levels could predict for the risk of cancer-related death and death from any cause [11]. It is a common clinical observation that anemia is frequent in cancer patients [13]. This could substantially increase the proportion of hypoxic cancer cells, leading to an intrinsic resistance to radiotherapy (RT) and chemotherapy (CT), with potential detrimental effects on treatment outcomes [14]. The impact of hemoglobin level in anal cancer patients submitted to CTRT has been rarely reported $[13,15]$. In the present study, we intended to investigate the influence of different clinical prognostic factors, particularly baseline hemoglobin (Hb) levels, on treatment outcomes within a cohort of anal cancer patients submitted to combined RT and CT.

\section{Methods}

\section{Patient selection}

We retrieved clinical data of patients treated for anal cancer at the Radiation and Medical Oncology Departments of 3 Italian institutions, namely University of Turin, AOU Citta' della Salute e della Scienza in Turin, Istituto Scientifico Romagnolo per lo Studio e la Cura dei Tumori (IRST) in Meldola and Modena Cancer Center in Modena. Briefly, all patients had a histologically confirmed diagnosis of squamous cell carcinoma located either within the anal canal or margin. Tumor stage was defined following the indications of the American Joint Committee on Cancer (2002 version) and patients with clinical stage T1-T4, N0-N3, M0 were included. Patients having clinical T1 N0 tumors of the anal margin were excluded, because generally treated with local excision.

\section{Staging}

Pre-treatment clinical evaluation included complete medical history, physical examination and complete laboratory testing. Staging included a chest, abdomen and pelvis computed tomography (CT) scan and a magnetic resonance imaging (MRI) of the pelvis with the adjunct of positron-emission tomography (PET) and/or inguinal sentinel lymphnode biopsy (SLNB) for systemic and nodal staging in specific cases.

\section{Patient evaluation}

Patients were followed-up according to local practice and vital status was clinically updated in 2018. Response to treatment was assessed at 4 time-points, namely at 6 weeks after CT-RT and thereafter at 3, 6 and 12 months [16]. Assessment comprised clinical and digital rectal examination, pelvic MRI and CT scan of the upper abdomen and thorax (for staging completion). Biopsy of any suspicious lesion detected at endoscopic examination was undertaken. Patients achieving a complete response (CR) were classified as 'complete responders' in case of clearance of all macroscopic disease for both primary tumor and regional lymphnodes and negative biopsy examination (when biopsy was performed). In case of residual tumor on imaging or positive biopsy after 6 months from CT-RT completion, patients having less than complete response (IR), were classified as 'incomplete responders'. Written informed consent for treatment was obtained for all patients. The Ethical Review Board of each Institutional Hospital approved the present study.

\section{Radiotherapy}

Two different approaches were used. At the University of Turin, patients were submitted to a simultaneous integrated boost (SIB)- based RT strategy and dose prescription was set according to the RTOG 05-29 indications modulated on clinical stage at presentation [17]. Patients with cT2N0 disease were given 50.4 Gy in 28 fractions (1.8 Gy daily) to the primary anal tumor, while the elective nodal volume was prescribed $42 \mathrm{~Gy}$ in 28 fractions (1.5 Gy/daily). Patients presenting cT3-T4/N0N3 disease were prescribed 54 Gy in 30 fractions (1.8 Gy daily) to the gross tumor volume, while gross nodal disease was prescribed 50.4 Gy in 30 fractions (1.68 Gy daily) if sized $\leq 3 \mathrm{~cm}$ or 54 Gy in 30 fractions (1.8 Gy daily) if $>3 \mathrm{~cm}$. Elective nodal volume was prescribed $45 \mathrm{~Gy}$ in 30 fractions (1.5 Gy daily) [14, 15]. Details and results of this treatment strategy have been previously published [18-20]. Patients treated at IRST in Meldola and Modena Cancer Center in Modena were given a first RT sequence of 45 Gy in 25 fractions (1.8 Gy daily) delivered over 5 weeks to the macroscopic primary and nodal tumor and prophylactic volumes (pelvic and inguinal nodes, ischio-anal fossa and mesorectum). In the second sequence, an adjunctive dose of 9-14.4 Gy in 58 fractions was delivered sequentially to the macroscopic disease up to a total nominal dose of 54-59.4 Gy.

\section{Chemotherapy}

All patients were treated according to the Nigro regimen. Hence, concomitant CT consisted of 5- fluorouracil (5-FU) $\left(1000 \mathrm{mg} / \mathrm{m}^{2} /\right.$ day $)$ given as continuous infusion for $96 \mathrm{~h}$ (days $1-5$ and 29-33) combined with mitomycin C (MMC) $\left(10 \mathrm{mg} / \mathrm{m}^{2}\right)$ given as bolus (days 1 and 29). Mitomycin $\mathrm{C}$ was capped at $20 \mathrm{mg}$ maximum 
dose. A total of 2 concurrent cycles were planned for each patient.

\section{Statistical analysis}

Baseline characteristics and clinical endpoints are presented for all patients. Discrete and continuous variables were summarized by frequencies and percentages and using standard measures of central tendency and dispersion (mean and standard deviation). The time-to-event functions were estimated by the Kaplan-Meier productlimit method. Cox proportional-hazard models were used to estimate the Hazard Ratios (HR) and the associated $95 \%$ confidence interval $(95 \% \mathrm{CI})$ both for the univariate and multivariate analysis. We used different analytic strategies for multivariate model implementation, namely forward, backward and stepwise approaches. Wald test and likelihood ratio tests for the case of nested models were used to assess significance of both single covariates and the model as a whole. Proportional hazard assumption was tested with visual inspection of log-log survival curves, plotted scaled Schoenfen's residuals and global Kolmogorov-Smirnov test. Collinearity among independent variables was evaluated with Fisher's exact test, t-test of difference between means and ANOVA, depending on the nature of the covariate. The following variables were investigated: age, gender, tumor and nodal stage, response to treatment, and overall treatment duration. Primary endpoints were progression free survival (PFS) and OS. Progression free survival was defined by the time interval between diagnosis and disease recurrence and/or progression at any site, death or lost at follow-up. Conversely, OS was calculated from the date of diagnosis to that of death from any cause or lost at observation. To assess the eventual correlation between the chance to achieve a CR and baseline $\mathrm{Hb}$ values, weighted linear regression was performed with pre-treatment $\mathrm{Hb}$ values as independent variable and the $C R$ rate in predefined group of patients as dependent variable. Patients were divided in 5 categories based on baseline $\mathrm{Hb}$ values $(<11 \mathrm{~g} / \mathrm{dl}$; 11-12 g/ $\mathrm{dl} ; 12-13 \mathrm{~g} / \mathrm{dl} ; 13-14 \mathrm{~g} / \mathrm{dl} ;>14 \mathrm{G} / \mathrm{dl})$. All the analyses were performed with 'rms' and 'survival' packages of $\mathrm{R}$ software environment (https://www.r-project.org).

\section{Results}

A total of 161 patients was analysed from 3 centers (49, 96 and 16 patients, respectively). No significant difference was found in terms of patient characteristics among the Institutions. Specifically, mean $\mathrm{Hb}$ values at baseline were $13.20 \mathrm{~g} / \mathrm{dl}(\mathrm{SD}: \pm 1.44), 12.90 \mathrm{~g} / \mathrm{dl}(\mathrm{SD}: \pm 1.57)$ and $12.85 \mathrm{~g} / \mathrm{dl}$ (SD: \pm 2.20$)$, respectively $(p=0.56)$.

Most of the patients were female (74.5\%), HIV negative $(94.4 \%)$ with a mean age of 62 . Most represented single global tumor stage was stage II (44.7\%), but locally advanced disease (stage IIIA and IIIB) was seen in up to $46.6 \%$ of patients (Table 1). Most of the patients (59.6\%) were treated with a SIB approach, with up to 54 Gy to the macroscopic tumor disease (60.4\%). Those treated with a sequential boost approach underwent a 9 Gy boost in $65.1 \%$ of the cases.

Almost all patients (98.1\%) were given 2 cycles of 5FU and MMC. Mean baseline $\mathrm{Hb}$ was $13.1 \mathrm{~g} / \mathrm{dl}$, while at the end of treatment mean value was $11.6 \mathrm{~g} / \mathrm{dl}$ (Table 2). With anemia as endpoint, acute hematologic toxicity was $\geq \mathrm{G} 2$ in $10 \%$ of the patients (Table 2).

Objective response, evaluated at the planned timepoint after the end of CT-RT, highlighted CR in $76.4 \%$ of

Table 1 Patient and tumor characteristics

\begin{tabular}{|c|c|}
\hline Variable & N (\%) \\
\hline \multicolumn{2}{|l|}{ Age } \\
\hline Mean & 62 \\
\hline Range & $36-83$ \\
\hline \multicolumn{2}{|l|}{ Sex } \\
\hline Female & $120(74.5)$ \\
\hline Male & $41(25.5)$ \\
\hline \multicolumn{2}{|l|}{ HIV status } \\
\hline Positive & $9(5.6)$ \\
\hline Negative & $152(94.4)$ \\
\hline \multicolumn{2}{|l|}{ T-stage } \\
\hline$T 1$ & $14(8.7)$ \\
\hline T2 & $90(56.0)$ \\
\hline T3 & $40(24.8)$ \\
\hline T4 & $15(9.3)$ \\
\hline$N A$ & $2(1.2)$ \\
\hline \multicolumn{2}{|l|}{$\mathrm{N}$-stage } \\
\hline NO & 91 (56.6) \\
\hline N1 & $26(16.1)$ \\
\hline N2 & $34(21.1)$ \\
\hline N3 & $10(6.2)$ \\
\hline \multicolumn{2}{|l|}{ Global stage } \\
\hline 1 & $13(8.1)$ \\
\hline$\|$ & $72(44.7)$ \\
\hline$I I I A$ & $29(18.0)$ \\
\hline$\| I B$ & 46 (28.6) \\
\hline$N A$ & $1(0.6)$ \\
\hline \multicolumn{2}{|l|}{ Grading } \\
\hline G1 & $12(7.5)$ \\
\hline G2 & 86 (53.4) \\
\hline G3 & 45 (27.9) \\
\hline$N A$ & 18 (11.2) \\
\hline
\end{tabular}

$N$ number, $T$-stage tumor stage, $N$-stage nodal stage, $N A$ not available 
Table 2 Hemoglobin levels and grade of anemia

\begin{tabular}{lll}
\hline Hb values & & \\
& Pre-treat & Post-treat \\
Mean $(g / d l)$ & 13.11 & 11.63 \\
Range $(g / d l)$ & $7.63-16.22$ & $8.44-14.71$ \\
Anemia (CTCAE v4.02) - N(\%) & & \\
NA & G0-G1 & G2-G3 \\
$10(6.2)$ & $135(83.8)$ & $16(10)$ \\
\hline
\end{tabular}

$H b$ hemoglobin, $g / d l$ grams/deciliter, pre-treat pre-treatment, post-treat post-treatment, $N$ number, CTCAE v4.02 Common Toxicity Criteria for Adverse Effects version 4.02

patients and IR in $23.6 \%$, respectively (Table 3 ). After a median follow up of 27 months (range: 1-30), the 3-year PFS and OS were 71.9\% (95\% CI:64.2\%-80.5\%) and 83. $1 \%$ (95\% CI:76.4\%-9.5\%), respectively. Five-year PFS and OS were $71.9 \%$ (95\% CI: $64.2 \%-80.5 \%)$ and $76.1 \%(95 \%$ CI: $67.3 \%-86.0 \%)$.

On univariate analysis, considering $\mathrm{Hb}$ as a continuous variable, a higher baseline $\mathrm{Hb}$ level significantly affected PFS (HR:0.57;95\% CI:0.39-0.85; $p=0.049$ ) and OS (HR:0. 53;95\% CI:0.29-0.96; $p=0.047)$. Moreover, achieving a CR after CT-RT significantly affected outcomes (Table 2). Specifically, obtaining a $C R$ was significantly associated to improved PFS (HR: 5.39;95\% CI:2.79-10.40; $p<$ $0.0001)$ and OS (HR: 6.26;95\% CI:2.73-14.40; $p<0.0001$ ) (Tables 4 and 5).

Results of the multivariate analyses were almost identical despite the different methods used (forward, backward and stepwise). On multivariate analysis, pre-treatment $\mathrm{Hb}$ level had a significant correlation to OS (HR:0.53;95\% CI:0.33-0. 87; $p=0.001$ ), but not to PFS (HR:0.78;95\% CI:0.53-1.15; $p=$ 0.12) (Tables 4 and 5). Response to treatment maintained a significant correlation to PFS (incomplete vs complete response - HR:5.43;95\% CI:2.75-10.7; $p<0.0001$ ) and OS (HR: 6.96;95\% CI:2.96-16.5; $p<0.0001)$. Comparison of mean pretreatment $\mathrm{Hb}$ values in patients having a $\mathrm{CR}$ (mean $\mathrm{Hb}$ : 13 . 2 g/dl; SD: \pm 1.12) or IR (mean Hb: 12.2 g/dl; SD: \pm 1.86 ) showed a significant difference (t-test; $p$ value $=0.043$ ). We also detected a significant correlation between basal $\mathrm{Hb}$ levels and lymph node status $(p=0.02)$. Both variables retained statistical significance in the multivariate model, suggesting an independent effect. In adjunct, the Variance Inflation Factor (VIF) was 1.1, indicating a low impact of this correlation on the results of the multivariable model.

Table 3 Objective response rate

\begin{tabular}{ll}
\hline Objective response & $N(\%)$ \\
\hline$C R$ & $123(76.4)$ \\
$\mathbb{R}$ & $38(23.6)$ \\
\hline$C R$ complete remission, $I R$ incomplete response &
\end{tabular}

Employing a cut-off point at $\mathrm{Hb}=12 \mathrm{~g} / \mathrm{dl}$, patients with pre-treatment $\mathrm{Hb} \geq 12 \mathrm{~g} / \mathrm{dl}$ had a 5 -year PFS of 82 . $2 \%$, compared to $29.3 \%$ for those with $\mathrm{Hb}<12 \mathrm{~g} / \mathrm{dl}$ (HR: 0.57; 95\% CI: 0.39-0.85; $p=0.0047$ ) (Fig. 1). Five-year OS was $82.2 \%$ for patients having $\mathrm{Hb} \geq 12 \mathrm{~g} / \mathrm{dl}$ and 32 . $8 \%$ for those having baseline $\mathrm{Hb}<12 \mathrm{~g} / \mathrm{dl}$ (HR:0.50; 95\% CI: $0.30-0.83 ; p=0.0065$ ) (Fig. 2). Weighted linear regression between $\mathrm{CR}$ rate and mean $\mathrm{Hb}$ values, showed a positive trend, with the likelihood of response increasing at higher $\mathrm{Hb}$ values $(p=0.11)$. We categorized patients in our cohort in 5 groups according to baseline Hb levels $(<11 \mathrm{~g} / \mathrm{dl}$; 11-12 g/dl; $12-13 \mathrm{~g} / \mathrm{dl} ; 13-14 \mathrm{~g} / \mathrm{dl}$; $>14 \mathrm{~g} / \mathrm{dl}$ ). Analyzing the slope of the linear regression curve and related intercept, the lowest $\mathrm{Hb}$ level category had a 55\% chance to achieve a CR after CT-RT. Interestingly, this likelihood increased by $5.6 \%$ for every singleunit $(\mathrm{g} / \mathrm{dl})$ increase in $\mathrm{Hb}$ level (Fig. 3).

Comparing outcomes according to response to treatment, both the 3- and 5-year PFS were $81.5 \%$ for patients achieving a CR compared to $43 \%$ for patients with incomplete response (Fig. 4). Three- and 5-year OS rates for the same response stratification were $93.1 \%$ and 85 . $4 \%, 56.6 \%$ and $51.4 \%$, respectively (Fig. 5).

\section{Discussion}

As pointed out by Glynne Jones et al., prognostic factors have to be intended as specific measurable characteristics that can be easily obtained and quantified during observation within a certain population to be potentially correlated to measures of clinical outcomes [11]. In anal cancer, prognostic factors have been described within retrospective series or randomized prospective phase III trials $[9,11,12]$. Some depend on tumor characteristics such as primary tumor dimension and nodal involvement, while others are intrinsic to the patient as for example gender. Hemoglobin level is a patient-related clinical factor that has not been extensively explored in anal cancer patients [15]. The correlation between $\mathrm{Hb}$ concentration and tumor oxygenation is well-established in several tumor types, with head and neck cancer being a paradigmatic example. [21, 22]. Anemia may enhance tumor hypoxia, increasing tumor cell radio-resistance and leading to a potentially more aggressive tumor phenotype [11]. This is well-known, for example, in cervical cancer, but evidence is also present for anal malignancies [23, 24]. Interestingly, in the RTOG 98-11 phase III trial, which explored the role of cisplatin concurrent to radiation and that of maintenance therapy, patients having levels of $\mathrm{Hb}$ below $10 \mathrm{~g} / \mathrm{dl}$ before randomization were excluded upfront from the study, because of the potential dismal prognosis [7]. In this sense, international clinical guidelines (such as those of the National Comprehensive Cancer Network) suggest the use of blood transfusion in symptomatic patients 
Table 4 Univariate and multivariate analysis for Overall Survival

\begin{tabular}{|c|c|c|c|c|}
\hline \multirow[b]{2}{*}{ Variable } & \multicolumn{2}{|l|}{ Univariate Analysis } & \multicolumn{2}{|c|}{ Multivariate Analysis } \\
\hline & $\operatorname{HR}(95 \% \mathrm{Cl})$ & $p$-value & $\operatorname{HR}(95 \% \mathrm{Cl})$ & $p$-value \\
\hline Age $>65$ & $1.44(0.64-2.43)$ & 0.58 & NA & NA \\
\hline Male sex & $2.23(1.42-3.05)$ & 0.01 & $3.66(1.56-8.60)$ & 0.002 \\
\hline $\begin{array}{l}\mathrm{G} 3 \text { vs } \mathrm{G} 1 \\
\mathrm{G} 2 \text { vs } \mathrm{G} 1\end{array}$ & $\begin{array}{l}1.36(0.58-3.21) \\
0.33(0.03-2.92)\end{array}$ & $\begin{array}{l}0.29 \\
0.32\end{array}$ & NA & NA \\
\hline T3-T4 vs T1-T2 & $1.94(0.88-4.25)$ & 0.12 & NA & NA. \\
\hline $\mathrm{N}+$ ve vs $\mathrm{N}$-ve & $2.11(1.31-2.90)$ & 0.02 & $2.25(1.00-5.17)$ & 0.049 \\
\hline RT total dose & $1.42(0.87-2.33)$ & 0.16 & NA & NA \\
\hline Boost: yes vs no & $1.72(0.40-7.35)$ & 0.47 & NA & NA \\
\hline $\mathrm{OTT}>42$ days & $1.75(0.86-2.65)$ & 0.19 & NA & NA \\
\hline $\mathrm{Hb}$ & $0.5(0.30-0.83)$ & 0.006 & $0.53(0.33-0.87)$ & 0.001 \\
\hline Response & $6.26(2.73-14.40)$ & $<0.0001$ & $6.96(2.96-16.50)$ & $<0.0001$ \\
\hline
\end{tabular}

RT Radiotherapy, $\mathrm{Hb}$ Basal haemoglobin levels ( $\mathrm{gr} / \mathrm{dl}$ ), Boost Radiotherapy boost: given vs not, Response Incomplete response vs complete response, OTT Total legth of chemo-radiation treatment, $N$ node, +ve positive, -ve negative, $H R$ hazard ratio, $C l$ confidence interval, $N A$ not available

with $\mathrm{Hb}$ levels below $10 \mathrm{~g} / \mathrm{dl}$, in order also to potentially enhance tumor re-oxygenation [25]. Our data seems to confirm these findings. On univariate analysis, baseline $\mathrm{Hb}$ levels, considered as a continuous variable, had a significant correlation to both PFS (HR:0.57;95\%CI:0.39-0. $85 ; p=0.049$ ) and OS (HR:0.53;95\% CI:0.29-0.96; $p=0$. 047). Conversely, on multivariate analysis, baseline $\mathrm{Hb}$ was significantly correlated only to OS (HR:0.50;95\% CI: 0.31-0.83; $p=0.0051$ ), but not to PFS (HR:0.80;95\% CI:0. $48-1.34 ; p=0.40$ ). The discrepancy observed for the correlation between pre-treatment $\mathrm{Hb}$ and OS vs PFS prompts to interrogate whether baseline $\mathrm{Hb}$ is a real independent prognostic factor or if it is just a surrogate parameter for patient's comorbid conditions or worse prognostic outcome. Nevertheless, it should be noted

Table 5 Univariate and multivariate analysis for Progression Free Survival

\begin{tabular}{|c|c|c|c|c|}
\hline \multirow[b]{2}{*}{ Variable } & \multicolumn{2}{|c|}{ Univariate Analysis } & \multicolumn{2}{|c|}{ Multivariate Analysis } \\
\hline & HR $(95 \%$ Cl) & $p$-value & HR (95\%Cl) & $p$-value \\
\hline Age $>65$ & $1.04(0.39-1.70)$ & 0.82 & NA & NA \\
\hline Male sex & $1.17(0.44-1.90)$ & 0.52 & NA & NA \\
\hline $\begin{array}{l}\mathrm{G} 3 \text { vs } \mathrm{G} 1 \\
\mathrm{G} 2 \text { vs } \mathrm{G} 1\end{array}$ & $\begin{array}{l}1.87(0.90-3.88) \\
1.76(0.51-6.10)\end{array}$ & $\begin{array}{l}0.92 \\
0.38\end{array}$ & $\begin{array}{l}\text { NA } \\
\text { NA }\end{array}$ & $\begin{array}{l}\text { NA } \\
\text { NA }\end{array}$ \\
\hline T3-T4 vs T1-T2 & $1.73(0.89-3.33)$ & 0.11 & NA & NA \\
\hline $\mathrm{N}+$ ve vs $\mathrm{N}$-ve & $2.16(1.18-3.96)$ & 0.012 & $1.98(1.01-3.88)$ & 0.046 \\
\hline RT total dose & $1.12(0.79-1.58)$ & 0.52 & NA & NA \\
\hline Boost: yes vs no & $0.84(0.32-2.18)$ & 0.72 & NA & NA \\
\hline $\mathrm{OTT}>42$ days & $1.18(0.53-1.85)$ & 0.38 & NA & NA \\
\hline $\mathrm{Hb}$ & $0.57(0.39-0.85)$ & 0.005 & $0.78(0.53-1.15)$ & 0.12 \\
\hline Response & $5.39(2.79-10.4)$ & $<0.0001$ & $5.43(2.75-10.70)$ & $<0.0001$ \\
\hline
\end{tabular}

RT Radiotherapy, $\mathrm{Hb}$ Basal haemoglobin levels (gr/dl), Boost Radiotherapy boost: given vs not, Response Incomplete response vs complete response, OTT Total legth of chemo-radiation treatment, $N$ node, $+v e$ positive, -ve negative, $H R$ hazard ratio, $\mathrm{Cl}$ confidence interval, NA not available that the results seems to suggest the presence of a correlation trend between $\mathrm{Hb}$ and PFS and hence, our hypothesis is that this observation can be due to the slenderness of the sample size in our study. We also cannot rule out an effect related to competing causes of death, as low $\mathrm{Hb}$ levels could be related to a 'frail' patient phenotype or worse clinical conditions predisposing to a higher likelihood of death from any cause, not strictly related to cancer. We also have to notice that we could detect a significant correlation between nodal involvement and baseline $\mathrm{Hb}$ levels. Again, we cannot fully rule out the possibility that this correlation could explain, at least partially, the poor PFS and OS related to $\mathrm{Hb}$ levels. However, both nodal statuts and $\mathrm{Hb}$ levels were comprised within the multivariable model, showing independent statistical significance. Moreover, the VIF for both PFS and OS showed very low values $(<1.1)$, strongly suggesting a limited influence of this correlation on the final outcome results. In our analysis, we employed a cut-off point at $\mathrm{Hb}=12 \mathrm{~g} / \mathrm{dl}$, which was able to allocate patients to different prognostic classes for both 5 -year PFS $(82.2 \%$ for $\mathrm{Hb} \geq 12 \mathrm{~g} / \mathrm{dl}$ vs $29.3 \%$ for $\mathrm{Hb}$ $<12 \mathrm{~g} / \mathrm{dl})$ and $\mathrm{OS}(82.2 \%$ for $\mathrm{Hb} \geq 12 \mathrm{~g} / \mathrm{dl}$ vs $32.8 . \%$ for $\mathrm{Hb}<12 \mathrm{~g} / \mathrm{dl}$ ). Our data are in line with those of Roldan et al. who found a significant correlation between pretreatment $\mathrm{Hb}$ levels and PFS and OS on univariate analysis, in a series of 72 anal cancer patients treated with concurrent CT-RT [15]. On multivariate analysis, lowest quartile pre-treatment $\mathrm{Hb}$ was a predictor for PFS, while pre-treatment $\mathrm{Hb}$ level was a significant predictor for OS. Interestingly, response to treatment at 3 months (together with nodal involvement and performance status) was confirmed as a significant predictor for both PFS and OS. Using baseline $\mathrm{Hb}$ values below $12 \mathrm{~g} / \mathrm{dl}$ as a cut- off point (only $10 \%$ of patients were below the cutoff), $\mathrm{Hb}$ levels remained significantly associated to OS 


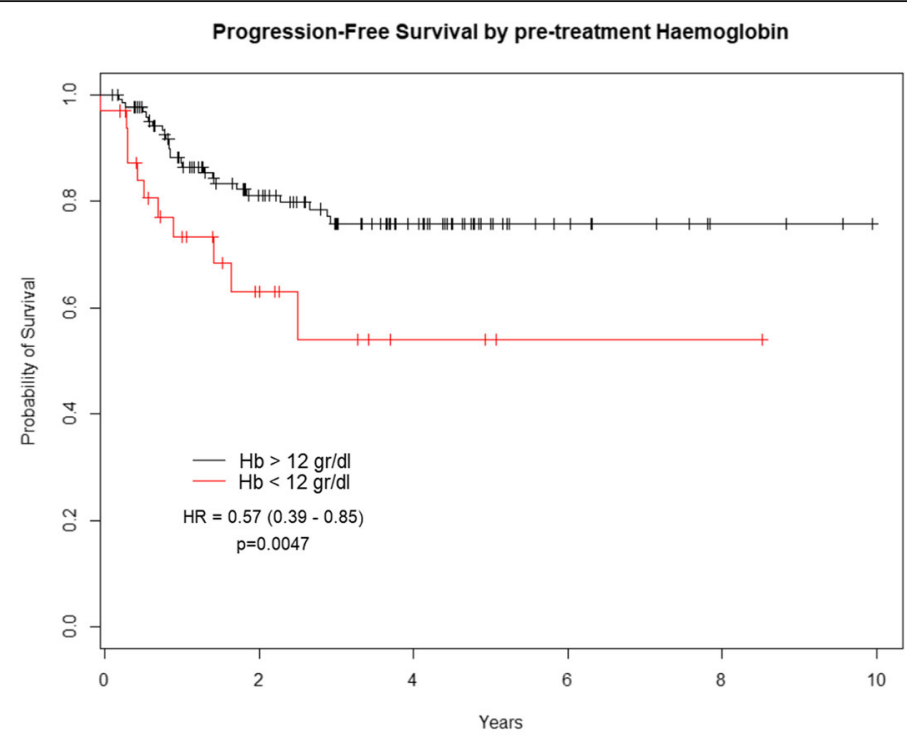

Number at Risk

\begin{tabular}{|c|c|c|c|c|c|}
\hline $\mathrm{Hb}>12 \mathrm{gr} / \mathrm{dl}$ & 128 & 71 & 34 & 10 & 3 \\
\hline $\mathrm{Hb}<12 \mathrm{gr} / \mathrm{dl}$ & 28 & 10 & 3 & 1 & 1 \\
\hline
\end{tabular}

Fig. 1 Progression free survival by baseline hemoglobin level

(log-rank $p=0.003)$ and PFS (log-rank $p<0.0001)$. In general, patients with pre-treatment $\mathrm{Hb}$ values in the lowest quartile had significantly worse PFS and OS than those whose values were in the 3 higher quartiles. A similar threshold was also found by Kapacee et al., in their series of 148 anal cancer patients treated CT-RT within the ACT-II trial (50.4 Gy/28 fractions delivered over 38 days concomitant to 5-FU and either MMC or DDP), where a pre-treatment $\mathrm{Hb}$ level $<13 \mathrm{~g} / \mathrm{dl}$ was found to predict for lower distant metastasis and cancerspecific survival $(p<0.05)$ [26]. Given the impact of both $\mathrm{CR}$ and baseline $\mathrm{Hb}$ level on treatment outcomes, we tried to quantify the relationship between these 2 clinical variables. After clustering patients in different groups

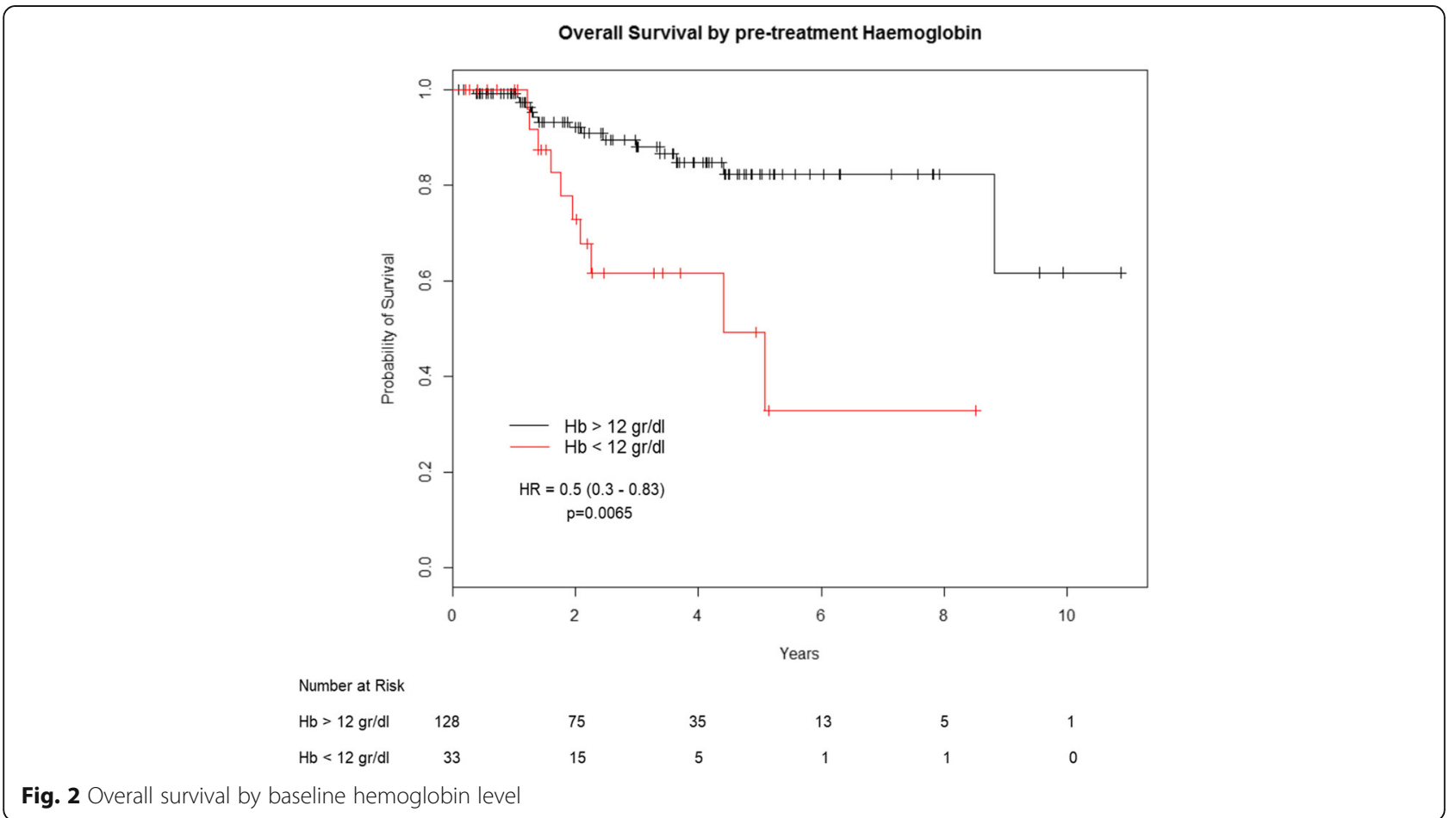




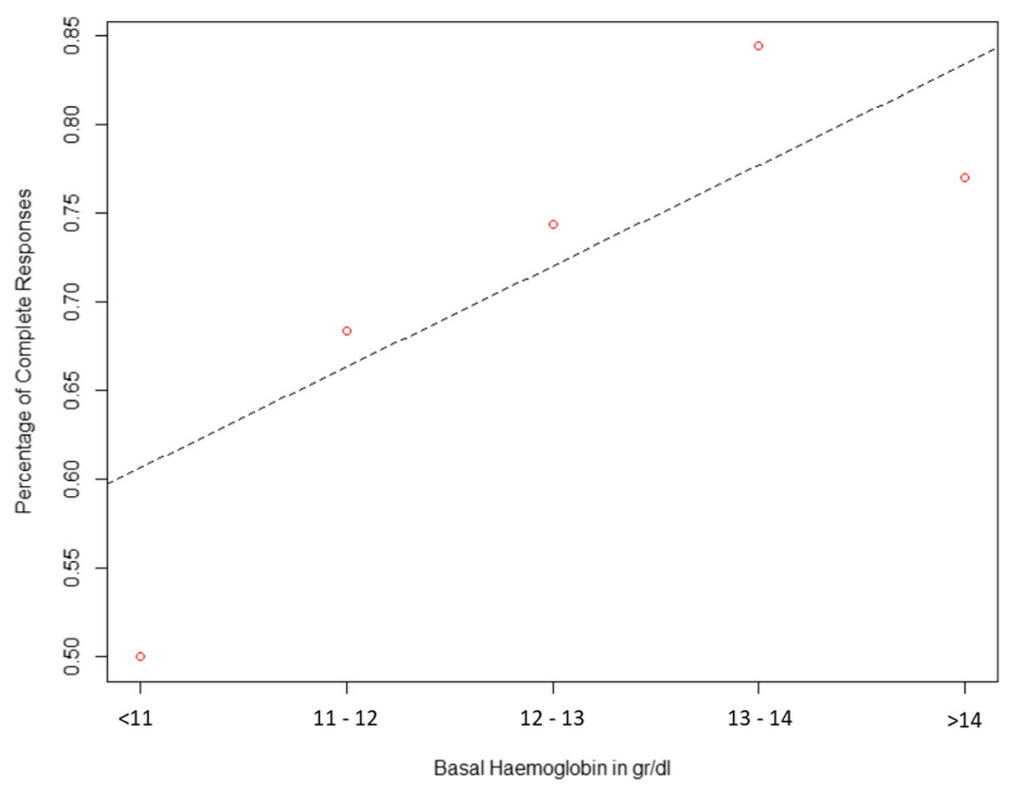

Fig. 3 Complete response rate plotted against baseline hemoglobin level

based on baseline $\mathrm{Hb}$ levels, we analyzed the slope of the linear regression curve and the intercept. The lowest $\mathrm{Hb}$ level category has a $55 \%$ chance to achieve a CR after CT-RT. Interestingly, this likelihood increases by $5.6 \%$ for every single-unit $(\mathrm{g} / \mathrm{dl})$ increase in $\mathrm{Hb}$ level. In our series response to treatment was found to be an independent predictor of PFS and OS, while baseline $\mathrm{Hb}$ level was found to independently predict OS but not PFS. Nevertheless, clinical response and baseline $\mathrm{Hb}$ seem to have a synergistic effect in determining survival, with higher pre-treatment $\mathrm{Hb}$ increasing the chance to achieve a CR and thus potentially affecting survival. This is in line with data coming from the ACT-I randomized phase III trial, which compared exclusive radiation to 5-FU/MMCbased concurrent CT-RT. In the analysis of prognostic factors performed within the study, baseline $\mathrm{Hb}$ level was shown as an independent prognostic factor for anal cancerrelated death [11]. After adjusting for sex and lymphnode

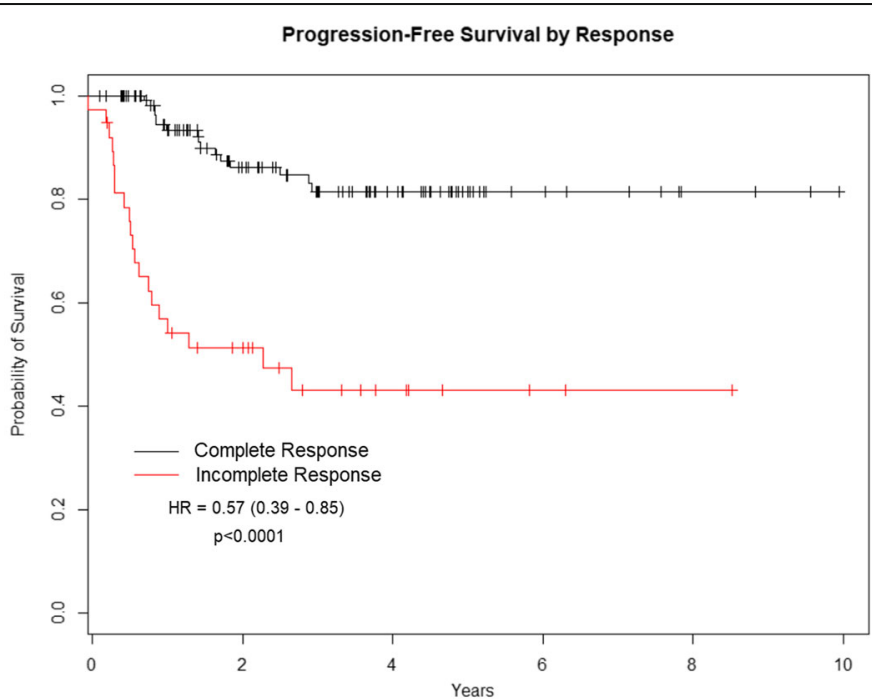

Number at Risk

Complete Response $\quad 121$

$68 \quad 52$

$52 \quad 22$

Incomplete Response 38

20

11

Fig. 4 Progression free survival by response to concurrent chemo-radiation 


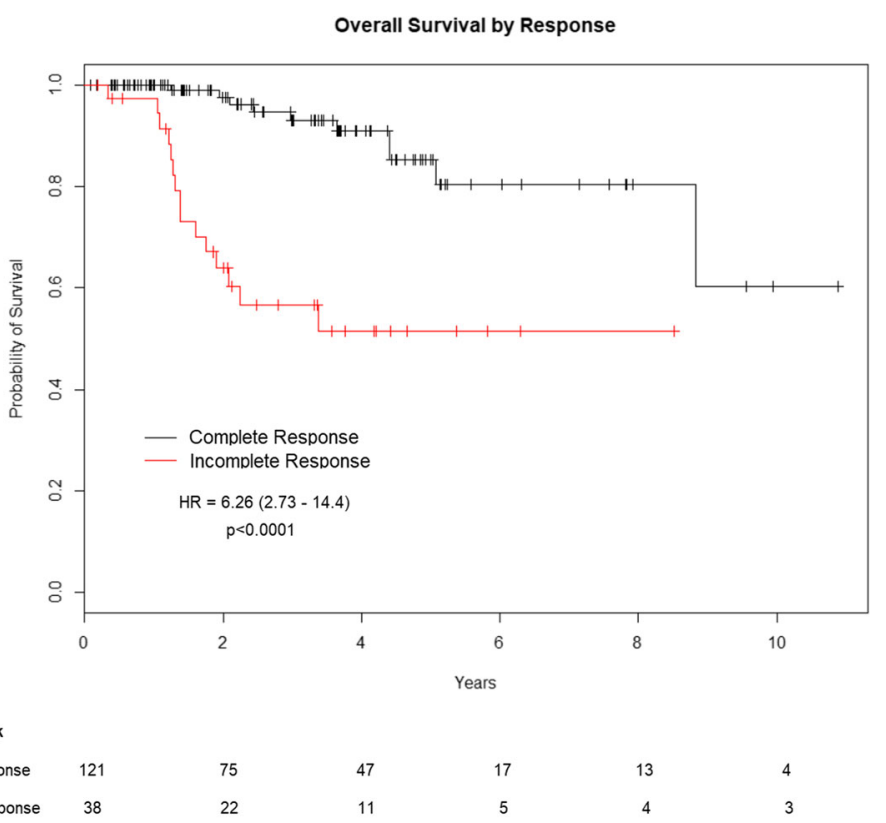

Fig. 5 Overall survival by response to concurrent chemo-radiation

status, Glynne-Jones et al. demonstrated that, on average, a single-unit $(\mathrm{g} / \mathrm{dl})$ increase in $\mathrm{Hb}$ was associated to a $19 \%$ reduction in the risk of anal cancer death [11].

In our study pre-treatment $\mathrm{Hb}$ levels were significantly correlated to overall survival. The HR we found at multivariate analysis (HR:0.5), was similar to that previously reported in other oncological settings [14]. That means that every patient has a $50 \%$ decrease in the risk of death at each time-point for a single unit increase in $\mathrm{Hb}$. Interestingly, such an effect is also observed for $\mathrm{Hb}$ levels above $11 \mathrm{~g} / \mathrm{dl}$, suggesting that even a slight, subclinical decrease in baseline $\mathrm{Hb}$ could significantly impair prognosis. Hemoglobin level is also associated to the likelihood of achieving a CR, which was found to be as the strongest independent prognostic factor for survival. The chance to achieve a CR increases by $5.6 \%$ for every single-unit $(\mathrm{g} / \mathrm{dl})$ increase in $\mathrm{Hb}$ level. On the contrary, lower $\mathrm{Hb}$ levels do predict for worse outcome. We cannot fully exclude other causes for the dismal prognosis seen in anemic patients. Baseline hemoglobin levels can be a mere consequence of a more aggressive biology of the tumor or a surrogate for patient's frailty or comorbid state. But at the same time baseline Hb levels seem to strongly predict for a higher likelihood to achieve a complete response to treatment. Probably, both aspects play a role in the final clinical outcome of the patient.

\section{Conclusions}

Our study has several limitations. At first, the small sample size did not allow us to perform subset analyses to better investigate the correlation between baseline $\mathrm{Hb}$ levels and other clinical variables potentially affecting treatment results. Secondly, the retrospective frame did not allow us to robustly check for eventual confounding factors. Another element, potentially influencing the results, is the different RT approach employed in the participating centers (simultaneous integrated boost vs sequential strategies), which implies different overall treatment times. The differential treatment length may be a factor influencing the relative strength in the correlation between baseline $\mathrm{Hb}$ and clinical outcomes. Moreover, we were not able to discriminate neither the different causes of anemia in our patients (iron deficiency, bleeding, nutritional status or chronic disease) nor the consequent treatment strategies employed to correct the deficit. This would have helped to better put into perspective the correlation between anemia and clinical outcomes [27]. Finally, we were not able to consistently track treatment breaks and modifications to have an idea on the eventual association with $\mathrm{Hb}$ levels and to monitor the clinical meaningfulness of the parameter $[28,29]$. Nevertheless, we were able to demonstrate that low baseline $\mathrm{Hb}$ levels are correlated to a higher likelihood to experience an incomplete response after treatment. Hence, objective response after CT-RT should be carefully monitored in these patients. Considering the poor prognosis associated to a lack of objective response to treatment and the significant impact on quality of life due to colostomy for those submitted to salvage surgery, we encourage oncologists to consider as a clinical priority the preservation of adequate $\mathrm{Hb}$ levels before starting CT-RT, but, possibly, during all phases of 
active therapy. To fully confirm this preliminary hypothesis, a prospective study having anemia correction as intervention is needed.

\author{
Abbreviations \\ 5-FU: 5-fluorouracil; CR: Complete response; CT: Chemotherapy; CT- \\ RT: Chemo-radiation; DDP: Cisplatin; DFS: Disease-free survival; \\ Hb: Hemoglobin; HR: Hazard ratio; LRR: Locoregional recurrence; \\ MMC: Mytomicin C; MRI: Magnetic resonance imaging; OS: Overall survival.; \\ PD: Progressive disease; PET: Positron-emission tomography; \\ PFS: Progression-free survival; PR: Partial response; RT: Radiotherapy; \\ SD: Stable disease; SIB: Simultaneous integrated boost; SLNB: Sentine \\ lymphnode biopsy
}

\section{Availability of data and materials}

Materials in the manuscript are available by contacting the corresponding author at pierfrancesco.franco@unito.it.

\section{Authors' contribution}

PF, FM, ACG, FA: study conception and design; CC, SM, GCI, KA, MS, LF: data collection; FM, PF, ACG: data analysis; PF,ACG,FM; manuscript draft; UR, SC, MM, PC: final revision and approval. All authors read and approved the fina manuscript.

\section{Ethics approval and consent to participate}

Approval for the present study was given by the Review Board of the Department of Oncology of the University of Turin. Written informed consent was acquired from all patients with respect to RT treatment and clinical data management for research purposes.

\section{Competing interest}

The authors declare that they have no competing interests.

\section{Publisher's Note}

Springer Nature remains neutral with regard to jurisdictional claims in published maps and institutional affiliations.

\section{Author details}

'Department of Oncology, Radiation Oncology, University of Turin at AOU Citta' della Salute e della Scienza, Via Genova 3, 10126 Turin, Italy. ${ }^{2}$ Department of Oncology, Medical Oncology, ASL Biella, Biella, Italy. ${ }^{3}$ Department of Oncology, Radiation Oncology, AOU Citta' della Salute e della Scienza, Turin, Italy. ${ }^{4}$ Department of Medical Oncology, Istituto Scientifico Romagnolo per lo Studio e la Cura dei Tumori (IRST) IRCCS, Meldola, Italy. ${ }^{5}$ Modena Cancer Center, Department of Oncology/ Hematology, University of Modena and Reggio Emilia, Modena, Italy. ${ }^{6}$ Department of Medical Oncology, University of Cagliari, Cagliari, Italy. ${ }^{7}$ Department of Surgical Sciences, University of Turin, Turin, Italy. ${ }^{8}$ Unit of Medical Oncology 2, Azienda Ospedaliero-Universitaria Pisana, Pisa, Italy. ${ }^{9}$ Department of Medical Sciences, Pathology Unit, University of Turin, Turin, Italy.

\section{Received: 16 January 2018 Accepted: 23 April 2018}

Published online: 02 May 2018

\section{References}

1. Jemal A, Siegel R, Ward E, et al. Cancer statistics. CA Cancer J Clin. 2008;258: 71-96.

2. Franco P, Arcadipane F, Ragona R, Mistrangelo M, Cassoni P, Rondi N, et al. Early-stage node negative (T1-T2NO) anal cancer treated with simultaneous integrated boost radiotherapy and concurrent chemotherapy. Anticancer Res. 2016:36:1943-8.

3. Franco P, Arcadipane F, Ragona R, Mistrangelo M, Cassoni P, Rondi N, et al. Locally advanced (T3-T4 or N+) anal cancer treated with simultaneous integrated boost radiotherapy and concurrent chemotherapy. Anticancer Res. 2016;36:2027-32.

4. UKCCCR Anal cancer Trial Working Party. UK Co-ordination Committee on Cancer Research: Epidermoid anal cancer: results from the UKCCCR randomized trial of radiotherapy alone versus radiotherapy, 5 -fluorouracil, and mitomycin. Lancet. 1996;348:1049-54.
5. Bartelink H, Roelofsen F, Eschwege F, Rougier P, Bosset JF, Gonzalez DG, et al. Concomitant radiotherapy and chemotherapy is superior to radiotherapy alone in the treatment of locally advanced anal cancer: results of a phase III randomized trial of the European Organization for Research and Treatment of Cancer radiotherapy and gastrointestinal cooperative group. J Clin Oncol. 1997;15:2040-9.

6. Flam M, John M, Pajak TF, Petrelli N, Myerson R, Doggett S, et al. Role of mytomicin in combination with fluorouracil and radiotherapy, and of salvage chemoradiation in the definitive nonsurgical treatment of epidermoid carcinoma of the anal canal: results of a phase III randomized intergroup study. J Clin Oncol. 1996;14:2527-39.

7. Ajani JA, Winter KA, Gunderson LL, Pedersen J, Benson AB 3rd, Thomas CR $J r$, et al. Fluorouracil, mitomycin, and radiotherapy vs fluorouracil, cisplatin, and radiotherapy for carcinoma of the anal canal: a randomized controlled trial. JAMA. 2008;299:1914-21.

8. James RD, Glynne-Jones R, Meadows HM, Cunningham D, Myint AS, Saunders MP, et al. Mitomycin or cisplatin chemoradiation with or without maintenance chemotherapy for treatment of squamous-cell carcinoma of the anus (ACTII): a randomised, phase 3, open-label, $2 \times 2$ factorial trial. Lancet Oncol. 2013;14:516-24.

9. Bilimoria KY, Bentrem DJ, Rock CE, Stewart AK, Ko CY, Halverson A. Outcomes and prognostic factors for squamous-cell carcinoma of the anal canal: analysis of patients for the National Cancer Data Base. Dis Colon rectum. 2009;52:624-31.

10. Johnson LG, Madeleine MM, Newcomer LM, Schwartz SM, Daling JR. Anal cancer incidence and survival: the surveillance, epidemiology and end results experience. Cancer. 2004;101:281-8.

11. Glynne-Jones R, Sebag-Montefiore D, Adams R, Gollins S, Harrison M, Meadows HM, et al. Prognostic factors for recurrence and survival in anal cancer. Cancer. 2013;119:748-55.

12. Ajani JA, Winter KA, Gunderson LL, Pedersen J, Benson AB 3rd, Thomas CR $\mathrm{Jr}$, et al. Prognostic factors derived from a prospective database dictate clinical biology of anal cancer. The intergroup trial (RTOG 98-11). Cancer. 2010;116:4007-13.

13. Oblak I, Cesnjevar M, Anzic M, Hadzic JB, Ermenc AS, Anderluh F, et al. The impact of anaemia on treatment outcome in patients with squamous cell carcinoma of the anal canal and anal margin. Radiol Oncol. 2016;50:113-20.

14. Hoff CM. Importance of hemoglobin concentration and its modification for the outcome of head and neck cancer patients treated with radiotherapy. Acta Oncol. 2012:51:419-32.

15. Roldan GB, Chan AK, Buckner M, Magliocco AM, Doll CM. The prognostic value of hemoglobin in patients with anal cancer treated with chemoradiotherapy. Dis Colon rectum. 2010;53:1127-34.

16. Glynne-Jones R, Sebag-Montefiore D, Meadows HM, Cunningham D, Begum $R$, Adab F, et al. Best time to assess complete clinical response after chemoradiotherapy in squamous cell carcinoma of the anus (ACT II): a posthoc analysis of randomised controlled phase 3 trial. Lancet Oncol. 2017; 18:347-56.

17. Kachnic LA, Winter K, Myerson RJ, Goodyear MD, Willins J, Esthappan J, et al. RTOG 0529: a phase 2 evaluation of dose-painted intensity modulated radiation therapy in combination with 5-fluorouracil and mytomycin C for the reduction of acute morbidity in carcinoma of the anal canal. Int J Radiat Oncol Biol Phys. 2013;86:27-33.

18. Franco P, Mistrangelo M, Arcadipane F, Munoz F, Sciacero P, Spadi R, et al. Intensity-modulated radiation therapy with simultaneous integrated boost combined with concurrent chemotherapy for the treatment of anal cancer patients: 4-year results of a consecutive case series. Cancer Investig. 2015;33: 259-66.

19. Franco P, Arcadipane F, Ragona R, Mistrangelo M, Cassoni P, Munoz F, et al. Volumetric modulated arc therapy (VMAT) in the combined modality treatment of anal cancer patients. Br J Radiol. 2016;89:2015832.

20. Arcadipane F, Franco P, Ceccarelli M, Furfaro G, Rondi N, Trino E, et al. Image-guided IMRT with simultaneous integrated boost as per RTOG 0529 for the treatment of anal cancer. Asia Pac J Clin Oncol Aug 30. doi: https:// doi.org/10.1111/ajco.12768. [Epub ahead of print] (2017).

21. Vaupel P, Mayer A, Hockel M. Impact of hemoglobin levels on tumor oxygenation: the higher, the better? Strahlenther Onkol. 2006;182:63-71.

22. Nordsmark M, Bentzen SM, Rudat V, Brizel D, Lartigau E, Stadler P, et al. Prognostic value of tumor oxygenation in 397 head and neck tumors after primary radiation therapy. An international multi-center study. Radiother Oncol. 2005;77:18-24. 
23. Bush $R$, Jenkin RD, Alt WE, Beale FA, Bean $H$, Dembo AJ, et al. Definitive evidence for hypoxic cells influencing cure in cancer therapy. Br J Cancer Suppl. 1978;3:302-6.

24. Constantinou EC, Daly W, Fung CY, Willett CG, Kaufman DS, DeLaney TF. Time-dose considerations in the treatment of anal cancer. Int J Radiat Oncol Biol Phys. 1997;39:651-7.

25. National Comprehensive Cancer Network (NCCN) Clinical Practice Guidelines in Oncology. Cancer- and chemotherapy-induced anemia. At www.nccn.org as accessed on 18th Dec 2017.

26. Kapacee ZA, Susnerwala M, Wise M, Biswas A, Danwata F, Scott N. Chemoradiotherapy for squamous cell anal carcinoma: a review of prognostic factors. Color Dis. 2016;18:1080-6.

27. Franco P, Arcadipane F, Ragona R, Mistrangelo M, Cassoni P, Racca P, et al. Hematologic toxicity in anal cancer patients during combined chemoradiation: a radiation oncologist perspective. Expert Rev Anticancer Ther. 2017;17:335-45

28. Franco P, Ragona R, Arcadipane F, Mistrangelo M, Cassoni P, Rondi N, et al. Dosimentric predictors of acute hematologic toxicity during concurrent intensity-modulated radiotherapy and chemotherapy for anal cancer. Clin Transl Oncol. 2017;19:67-75.

29. Franco P, Arcadipane F, Ragona R, et al. Dose to specific subregions of pelvic bone marrow defined with FDG-PET as a predictor of hematologic nadirs during concomitant chemoradiation in anal cancer patients. Med Oncol. 2016;33:72

Ready to submit your research? Choose BMC and benefit from:

- fast, convenient online submission

- thorough peer review by experienced researchers in your field

- rapid publication on acceptance

- support for research data, including large and complex data types

- gold Open Access which fosters wider collaboration and increased citations

- maximum visibility for your research: over $100 \mathrm{M}$ website views per year

At BMC, research is always in progress.

Learn more biomedcentral.com/submissions 